\title{
LIVROS LITERÁRIOS INFANTIS SOBRE O CUIDADO COM OS ANIMAIS SENCIENTES NÃO-HUMANOS: O QUE ELES TÊM A DIZER?
}

Aline Miranda da Silva ${ }^{1}$

Resumo: Um dos elos que liga várias espécies de animais é a senciência. Contudo, pela lógica especista, a dor e o sofrimento infligidos aos animais sencientes não-humanos são desqualificados e ignorados. Em oposição a essa lógica, o presente trabalho apresentou dezesseis livros literários infantis sobre o cuidado com os animais sencientes não-humanos, como potenciais recursos pedagógicos para a Educação Ambiental crítica de crianças.

Palavras-chave: Senciência; Livros Infantis; Educação Ambiental Crítica.

Abstract: One of the links that connect various species of animals is sentience. However, by speciesist logic, the pain and suffering inflicted on non-human sentient animals is disqualified and ignored. In opposition to this logic, the present work presented sixteen children's literary books on the care of nonhuman sentient animals, as potential pedagogical resources for critical environmental education for children.

Keywords: Sentience; Children's book; Critical Environmental Education. 


\section{Introdução}

Um dos elos que liga várias espécies de animais é a senciência, definida como "a capacidade [do indivíduo] de sentir, estar consciente de si próprio ou apenas do ambiente que o cerca" (LUNA; 2008, p. 18).

Apesar disso, nossas relações com os animais não-humanos são marcadas pela lógica antropocêntrica que exalta a racionalidade humana em contraposição à natureza orgânica, da qual fazemos parte (BEHLING; CAPORLINGUA, 2019).

No caso dos animais consumidos na alimentação humana, é importante ressaltar que eles se tornam, na maioria das vezes, referenciais ausentes (LESSA; CAMARGO, 2014, p. 383):

A função do referencial ausente é manter a carne separada de qualquer ideia de que ela era um animal. As mulheres são referenciais ausentes em nossa cultura também, sendo vistas como um corpo a ser consumido e usado pela publicidade e de muitos outros modos.

De maneira geral, a discriminação contra os animais não-humanos é pautada pelo especismo (SINGER, 2013, p. 15):

Os racistas violam o princípio da igualdade ao conferir mais peso aos interesses de membros de sua etnia quando há um conflito entre os próprios interesses e os daqueles que pertencem a outras etnias. Os sexistas violam o princípio da igualdade ao favorecer os interesses do próprio sexo. Analogamente, os especistas permitem que os interesses de sua espécie se sobreponham aos interesses maiores de membros de outras espécies. O padrão é idêntico em todos os casos.

$\mathrm{Na}$ escola, por exemplo, o sistema de crenças especista é reforçado desde a Educação Infantil, sendo facilmente identificado "nos componentes curriculares, nos materiais didáticos, nas falas das professoras, na escolha dos passeios, nas refeições, nas celebrações culturais" (MELLO; DIAS, 2020, p. 212).

Desse modo, é urgente que as pessoas tenham acesso a uma Educação Ambiental crítica que desnaturalize a dominação e opressão pela qual os animais sencientes não-humanos são submetidos. Além do planejamento cuidadoso das ações, essa educação dialógica deve levar em consideração quatro elementos fundamentais: empatia, ética, criticidade e não violência (CASTELLANO; SORRENTINO, 2013). 
As questões animalistas podem ser trazidas à tona por meio de temas como "maus tratos e abandono de animais", "uso dos mesmos para alimentação, fins científicos ou religiosos", "casos em que ocorrem crimes e as situações em que se deve proceder à denúncia" (RODRIGUES, 2018).

Entretanto, é preciso promover atividades que levem em conta a singularidade/complexidade/subjetividade das espécies de animais, bem como que questionem as práticas pedagógicas e materiais didáticos especistas amplamente adotados nas escolas (MELLO; DIAS, 2020. ANZOATEGUI; GONZÁLEZ; BORDET, 2019).

Sobre a zooliteratura infantil contemporânea, é sabido que ela pode contribuir com a oferta de livros que proponham uma verdadeira comunhão entre todos os animais, humanos ou não. Isso porque os animais não-humanos pertencem à gênese do mundo infantil, a partir do encantamento e curiosidade sobre seus sons, formas e texturas (COUTINHO, 2016).

Nesse sentido, o presente trabalho propõe-se a apresentar títulos de livros literários infantis, os quais versam sobre o cuidado com os animais sencientes não-humanos, como potenciais recursos pedagógicos para a Educação Ambiental crítica de crianças.

\section{Materiais e Métodos}

A seleção dos títulos foi feita no mês de novembro de 2020, mediante buscas no Google com as palavras-chave: "livros sobre cuidado com os animais" e "livros educação animalista para crianças".

A partir do redirecionamento para páginas de lojas virtuais, foram utilizados como critérios de seleção:

- Indicação da faixa etária própria para crianças;

- Autores brasileiros - tendo em vista histórias mais condizentes com a realidade nacional;

- Sinopses alinhadas à ótica abolicionista animal e Educação Ambiental crítica;

- Livros disponíveis para compra.

Após o processo de seleção, foram feitas as aquisições e análises das obras, entre dezembro de 2020 e janeiro de 2021, levando-se em consideração os pontos de convergência e divergência entre elas, além de suas potencialidades como recursos na promoção de uma Educação Ambiental crítica. 


\section{Resultados e Discussão}

Partindo-se dos critérios elencados, anteriormente, foram selecionados dezesseis títulos de livros literários infantis sobre o cuidado com os animais sencientes não-humanos (Quadro 1).

Quadro 1: Títulos de livros literários infantis sobre o cuidado com os animais sencientes nãohumanos

\begin{tabular}{|c|c|c|c|}
\hline Título & Autoria e ilustração & Faixa etária & $\begin{array}{l}\text { Disponível } \\
\text { no site do(a) }\end{array}$ \\
\hline $\begin{array}{l}\text { Amiga ursa: uma história triste, } \\
\text { mas com final feliz }\end{array}$ & $\begin{array}{l}\text { Rita Lee e Guilherme } \\
\text { Francini }\end{array}$ & $\begin{array}{c}\text { A partir dos } 6 \\
\text { anos }\end{array}$ & Amazon \\
\hline $\begin{array}{l}\text { Amigo não abandona outro amigo } \\
\text { Cuidar de alguém nos deixa feliz }\end{array}$ & \multirow{2}{*}{$\begin{array}{l}\text { Cristina Cabral/Maria } \\
\text { Helena Querido e } \\
\text { Vanessa Alexandre }\end{array}$} & \multirow[t]{2}{*}{ 3-10 anos } & \multirow[t]{2}{*}{ Amazon } \\
\hline $\begin{array}{l}\text { Os animais sentem tudo o que } \\
\text { você sente }\end{array}$ & & & \\
\hline $\begin{array}{l}\text { Pessoas e Animais, Amizades } \\
\text { Legais: Gary }\end{array}$ & \multirow{6}{*}{$\begin{array}{ll}\text { Paulo } & \text { Roberto } \\
\text { Drummond e Daniela } \\
\text { Benite }\end{array}$} & \multirow[t]{6}{*}{ 3-11 anos } & \multirow{6}{*}{$\begin{array}{c}\text { Loja do } \\
\text { Projeto PAZ- } \\
\text { Pessoas e } \\
\text { Animais, } \\
\text { amiZades } \\
\text { legais }\end{array}$} \\
\hline $\begin{array}{l}\text { Pessoas e Animais, Amizades } \\
\text { Legais: George }\end{array}$ & & & \\
\hline $\begin{array}{l}\text { Pessoas e Animais, Amizades } \\
\text { Legais: Ismael }\end{array}$ & & & \\
\hline $\begin{array}{l}\text { Pessoas e Animais, Amizades } \\
\text { Legais: Jill }\end{array}$ & & & \\
\hline $\begin{array}{l}\text { Pessoas e Animais, Amizades } \\
\text { Legais: Márcia }\end{array}$ & & & \\
\hline $\begin{array}{l}\text { Pessoas e } \text { Animais, Amizades } \\
\text { Legais: Vera }\end{array}$ & & & \\
\hline Nós adoramos as segundas-feiras & $\begin{array}{l}\text { Tânia Veiga Judar e } \\
\text { Bruna Assis Brasil }\end{array}$ & $\begin{array}{l}\text { A partir dos } 8 \\
\text { anos }\end{array}$ & $\begin{array}{c}\text { Loja da } \\
\text { Sociedade } \\
\text { Vegetariana } \\
\text { Brasileira }\end{array}$ \\
\hline $\begin{array}{l}\text { O que você sentiria se tivesse que } \\
\text { viver assim? }\end{array}$ & $\begin{array}{l}\text { Regina de Toledo e } \\
\text { Luis Élson Dantas } \\
\end{array}$ & $\begin{array}{c}\text { A partir dos } 9 \\
\text { anos }\end{array}$ & $\begin{array}{l}\text { Editora } \\
\text { IMEPH } \\
\end{array}$ \\
\hline $\begin{array}{l}\text { A paz mundial começa na cozinha: } \\
\text { Quem é o pato }\end{array}$ & $\begin{array}{l}\text { Regina de Toledo e } \\
\text { Seva Kunja dd }\end{array}$ & $\begin{array}{l}\text { A partir dos } 9 \\
\text { anos }\end{array}$ & $\begin{array}{l}\text { Clube de } \\
\text { autores }\end{array}$ \\
\hline $\begin{array}{l}\text { A paz mundial começa na cozinha: } \\
\text { Quem é o peixe }\end{array}$ & & & \\
\hline $\begin{array}{l}\text { A paz mundial começa na cozinha: } \\
\text { Quem é a tartaruga }\end{array}$ & & & \\
\hline $\begin{array}{l}\text { A paz mundial começa na cozinha: } \\
\text { Quem é o peru }\end{array}$ & & & \\
\hline
\end{tabular}

Fonte: a autora.

Com relação às análises dos títulos supracitados, a responsabilidade com o cuidado dos animais sencientes não-humanos foi evidenciada para além do fornecimento de água, comida e abrigo. Outras características tão importantes, como higiene, saúde e carinho, também foram salientadas para as crianças que se dispuserem a cuidar de um ou mais animais. 
Ademais, chama-se atenção para o fato de os livros tratarem do cuidado com outras espécies de animais e não apenas cães e gatos, marcadamente reconhecidos como animais de estimação em culturas ocidentais (JOY, 2014).

É importante ressaltar que, em todos os títulos, os protagonistas nãohumanos possuíam um nome próprio, o que ajudou na construção de suas identidades como sujeitos de direitos e na oposição de convertê-los em referencias ausentes, no caso daqueles explorados para a alimentação humana (ADAMS, 2018).

Outro ponto de convergência entre as obras foi que todas trataram da senciência dos animais não-humanos. Apesar de que, no livro "Nós adoramos as segundas-feiras" (JUDAR, 2015), o maior enfoque tenha sido para os impactos ambientais decorrentes da pecuária.

Embora os autores tenham escrito histórias permeadas pela ótica abolicionista animal, Toledo $(2010 ; 2013)$ foi a mais veemente ao propor o veganismo como forma de combater o sofrimento causado pela exploração dos animais sencientes não-humanos.

Também, deve-se levar em conta que apenas um título tratou da exploração animal em circos e zoológicos (LEE, 2019). Ele nos lembra que, "podemos questionar os passeios tradicionais a zoológicos, minifazendas e aquários, debatendo e desmistificando o papel desses locais de confinamento e tristeza como espaços educativos" (MELLO; DIAS, 2020, p. 226).

Como uma alternativa em relação aos zoológicos, Lee (2019) e Toledo (2013) nos apresentam os santuários de animais, os quais são definidos como:

Santuários são locais sem fins lucrativos onde animais são reabilitados após serem vítimas de maus-tratos e exploração em circos ou no tráfico. Eles são tratados e, na maioria dos casos, reintroduzidos na natureza.

Diferentemente de zoológicos, os animais não são expostos e não ficam presos. Uma das características principais dos santuários é a criação de um habitat no qual os animais se sintam na natureza. O objetivo é que, ao final da reabilitação, o animal consiga conviver no ambiente externo de uma maneira mais natural e saudável (OLIVEIRA, 2019).

Há que se destacar, ademais, a história da coelhinha Vera (DRUMMOND, 2018), a qual demonstrou que nem sempre o melhor para os animais não-humanos é estar sobre a tutela dos seres humanos, por mais bem-intencionados que sejamos. Essa foi uma das histórias com desfecho mais surpreendente, pois rompeu com a ideia, também antropocêntrica, da imprescindibilidade humana para atender aos interesses dos outros animais (BEHLING; CAPORLINGUA, 2019). 
Pelas características dos títulos analisados, pode-se afirmar que eles são bons candidatos para o desenvolvimento de práticas de Educação Ambiental crítica junto às crianças, seja em espaços formais quanto em nãoformais (conforme preconizado pela lei 9795/99).

No entanto, tomando-se como referência as orientações propostas por Santos (2019), alguns aspectos devem ser observados nas atividades que prevejam a abordagem sobre o cuidado com os animais sencientes nãohumanos:

- Atividades planejadas visando à participação ativa das crianças;

- Evitar conteúdos expositivos;

- Levá-las a responder perguntas que as façam refletir sobre os cenários apresentados;

- Incitá-las a se posicionarem sobre determinados eventos, tomando em consideração a perspectiva do animal e o olhar ao outro.

\section{Conclusão}

Nesse trabalho, foi possível verificar que o cuidado com os animais sencientes não-humanos é uma temática possível e urgente de ser contemplada na Educação Ambiental crítica de crianças.

É bem provável que os títulos de livros literários infantis, aqui apresentados, sejam desconhecidos pela maior parte dos educadores ambientais, bem como do grande público em geral. Desse modo, como forma de evidenciar mais recursos didáticos que versam sobre essa temática, futuras análises de livros e outros materiais devem ser empreendidas.

Não devemos jamais desconsiderar as discriminações que acontecem entre membros da nossa espécie, mas, um mundo mais ético e justo, que tanto almejamos, passa pelo combate às formas de exploração direcionadas aos animais sencientes não-humanos.

\section{Referências}

ADAMS, C. J. A política sexual da carne: uma teoria feminista-vegetariana. Tradução: Cristina Cupertino. 2 ed. São Paulo: Editora Alaúde, 2018. 384 p.

ANZOÁTEGUI, M.; GONZÁLEZ, G. Y.; BORDET, M. V. É possível ensinar de maneira não antropocêntrica?: uma questão na era do Antropoceno. Revista Latinoamericana de Estudios Críticos Animales. 2019, p.10-17.

BEHLING, G. M.; CAPORLINGUA, V. H. Educação Ambiental Crítica e a transição paradigmática do direito ambiental na desobjetificação dos animais. Revista Ambiente \& Sociedade. V.22, n.1, p.1-18, 2019. 
BRASIL. Lei no 9795, de 27 de abril de 1999. Dispõe sobre a Educação Ambiental, institui a Política Nacional de Educação Ambiental e dá outras providências. Diário Oficial da União, Brasília, DF, 28 abr. 1999. Disponível em: $<$ http://www.planalto.gov.br/ccivil 03/leis/19795.htm>. Acesso: 23 jan. 2021.

CABRAL, C.; QUERIDO, M. H. Amigo não abandona outro amigo: adotar um animal é uma grande decisão. Projeto gráfico e ilustrações: Vanessa Alexandre. São Paulo: Cabral \& Querido, 2020. 43 p.

CABRAL, C.; QUERIDO, M. H. Cuidar de alguém me deixa feliz: respeito e responsabilidade com os animais. Projeto gráfico e ilustrações: Vanessa Alexandre. São Paulo: Cabral \& Querido, 2020. 44 p.

CABRAL, C.; QUERIDO, M. H. Os animais sentem tudo o que você sente: os animais têm sentimentos. Projeto gráfico e ilustrações: Vanessa Alexandre. São Paulo: Cabral \& Querido, 2020. 44 p.

CASTELLANO, M.; SORRENTINO, M. Como ampliar o diálogo sobre o abolicionismo animal? Contribuições pelos caminhos da educação e das políticas públicas. Revista Educação e Direito Animal. V.8, n.14, p.133-160, 2013;

COUTINHO, F. Os animais que todos somos: ou a vida dos bichos na literatura infantil contemporânea. Revista Estação Literária. 2016, p.73-85.

DRUMMOND, P. R. Pessoas e Animais, Amizades Legais: Gary. Ilustrações: Daniela Benite. São Paulo: edição do autor, 2018. 20 p.

DRUMMOND, P. R. Pessoas e Animais, Amizades Legais: George. llustrações: Daniela Benite. São Paulo: edição do autor, 2018. 36 p.

DRUMMOND, P. R. Pessoas e Animais, Amizades Legais: Ismael. llustrações: Daniela Benite. São Paulo: edição do autor, 2018. 32 p.

DRUMMOND, P. R. Pessoas e Animais, Amizades Legais: Jill. llustrações: Daniela Benite. São Paulo: edição do autor, 2018. 20 p.

DRUMMOND, P. R. Pessoas e Animais, Amizades Legais: Márcia. llustrações: Daniela Benite. São Paulo: edição do autor, 2018. 36 p.

DRUMMOND, P. R. Pessoas e Animais, Amizades Legais: Vera. llustrações: Daniela Benite. São Paulo: edição do autor, 2018. 20 p.

JOY, M. Porque amamos cachorros, comemos porcos e vestimos vacas: uma introdução ao carnismo: o sistema de crenças que nos faz comer alguns animais e outros não. Tradução: Mário Molina. 1 ed. São Paulo: Cultrix, 2014. p. 32.

JUDAR, T. V. Nós adoramos as segundas-feiras. Ilustrações: Bruna Assis Brasil. 1 ed. São Paulo: Cuore, 2015. 64 p.

LEE, R. Amiga ursa: uma história triste, mas com final feliz. Ilustrações: Guilherme Francini, 1 ed. São Paulo: Editora Globo, 2019. 
LESSA, P.; CAMARGO, M. Uma teoria feminista-vegana: a política sexual da carne. Revista Estudos Feministas. V.22, n.1, p.361-391, 2014.

LUNA, S. P. L. Dor, senciência e bem-estar em animais: senciência e dor. Revista Ciência Veterinária nos Trópicos. V.11, n.1, p.17-21, 2008.

MELLO, A. L. G. D.; DIAS, R. O. Por uma formação inventiva antiespecista. Revista Mnemosine. V.16, n.1, p.208-231, 2020.

OLIVEIRA, C. Você sabe qual a diferença entre zoológico e santuário de animais? 2019. Disponível em: <https://mercyforanimals.org.br/blog/voc-sabequal-a-diferena-entre-zoolgico-e-2/>. Acesso: 23 jan. 2021.

SANTOS, M. B. P. Amigos da onça: utilizando a figura da onça-pintada para debater direitos animais e preservação ambiental na Educação Infantil. Revista Experiências em Ensino de Ciências. V.14, n.2, p.139-151, 2019.

SINGER, P. Libertação Animal. Tradução: Marly Winckler, Marcelo Brandão Cipolla; Revisão Técnica: Rita Paixão. 2 ed. São Paulo: Editora WMF Martins Fontes, 2013. p. 15.

TOLEDO, R. 0 que você sentiria se tivesse que viver assim? llustrações: Luis Élson Dantas. 1 ed. Fortaleza: Editora IMEPH, 2010. 104 p.

TOLEDO, R. A paz mundial começa na cozinha: Quem é o pato. Ilustrações: Seva Kunja dd. 1 ed. v. 4. Joinville: Clube de Autores Publicações S/A, 2013. $41 \mathrm{p}$.

TOLEDO, R. A paz mundial começa na cozinha: Quem é o peru. llustrações: Seva Kunja dd. 1 ed. v. 5. Joinville: Clube de Autores Publicações S/A, 2013. $38 \mathrm{p}$.

TOLEDO, R. A paz mundial começa na cozinha: Quem é o peixe. llustrações: Seva Kunja dd. 1 ed. v. 6. Joinville: Clube de Autores Publicações $\mathrm{S} / \mathrm{A}, 2013.43 \mathrm{p}$.

TOLEDO, R. A paz mundial começa na cozinha: Quem é a tartaruga. llustrações: Seva Kunja dd. 1 ed. v. 7. Joinville: Clube de Autores Publicações $\mathrm{S} / \mathrm{A}, 2013.45 \mathrm{p}$. 